\title{
Simulation on phosphorus release characteristics of Poyang Lake sediments under variable water levels and velocities
}

\author{
TONG Yali, LIANG Tao, "WANG Lingqing, "LI Kexin
}

Key Laboratory of Land Surface Pattern and Simulation, Institute of Geographic Sciences and Natural Resources Research, CAS, Beijing 100101, China

\begin{abstract}
Since the construction of the Three Gorges Dam, the Poyang Lake hydrological characteristics obviously changed. During the impoundment period of the Three Gorges Reservoir, the hydrodynamic factors of Poyang Lake varied. Water level dropped, the velocity decreased and water exchange time lengthened, which changed the release of phosphorous from sediments. In order to investigate how the hydrodynamic factors influence the release of phosphorous from sediments, we used a two-way annular flume device to simulate the release characteristics of phosphorous from sediments under variable water levels and velocities. We found that both water level rising and velocity increasing could enhance the disturbance intensity to sediments, which caused the increase of suspended solids (SS) concentration, total phosphorus (TP) concentration in the overlying water, and the ability that phosphorus released to overlying water from sediments enhanced as well: when overlying water velocity maintained $0.3 \mathrm{~m} / \mathrm{s}$, SS concentration increased to $4035.85 \mathrm{mg} / \mathrm{L}$ at the water level $25 \mathrm{~cm}$ which was about 25 times compared to the minimum value and TP concentration in the overlying water also reached the maximum value at the water level $25 \mathrm{~cm}$ which was 1.2 times that of the value at $10 \mathrm{~cm}$; when water level maintained $15 \mathrm{~cm}$, SS concentration increased to $4363.35 \mathrm{mg} / \mathrm{L}$ at the velocity of $0.5 \mathrm{~m} / \mathrm{s}$ which was about 28 times compared to the value of $0 \mathrm{~m} / \mathrm{s}$, and TP concentration in the overlying water increased from $0.11 \mathrm{mg} / \mathrm{L}$ to 0.44 $\mathrm{mg} / \mathrm{L}$. When the water level maintained $15 \mathrm{~cm}$, the phosphorous release rate reached the maximum value of $4.86 \mathrm{mg} /(\mathrm{md})$ at $0.4 \mathrm{~m} / \mathrm{s}$. The concentration of total dissolved phosphorous (TDP) and soluble reactive phosphate (SRP) both in overlying water and sediment-water interface were negatively correlated with $\mathrm{pH}$. Using the parabolic equation, the optimum water level at a velocity of $0.3 \mathrm{~m} / \mathrm{s}$ was calculated to be $0.57 \mathrm{~cm}$, and the optimum velocity at water level of $15 \mathrm{~cm}$ was found to be $0.2 \mathrm{~m} / \mathrm{s}$.
\end{abstract}

Keywords: hydrodynamic factors, sediment-water interface, total phosphorous, total dissolved phosphorous, soluble reactive phosphate, Poyang Lake

Received: 2016-06-15 Accepted: 2016-08-20

Foundation: National Key Project for Basic Research, No.2012CB417004

Author: Tong Yali, MS, specialized environmental geography. E-mail: tongyali123@163.com

"Corresponding author: Wang Lingqing, E-mail: wanglq@igsnrr.ac.cn; Li Kexin, likx@igsnrr.ac.cn 


\section{Introduction}

The increase of nutrients in lake is the main reason that why lake eutrophication emerges (Wetzel, 2001; Xing et al., 2005). Generally, when the ration of N/P in lake is larger than 10, phosphorous is the limited element of eutrophication (Chen et al., 2005). Investigations on global lakes have confirmed that $80 \%$ of the nutrition level is controlled by phosphorus, another $10 \%$ has a direct relationship to phosphorus and nitrogen, and the remaining $10 \%$ is influenced by other factors (Reddy et al., 1996; Wetzel, 2001; Kim et al., 2007). The source of phosphorous in lake water body includes internal source and external source, and the internal source of phosphorous in a lake has been proven to be a large proportion of the total phosphorous input (Sundby et al., 1992; Carrick et al., 1993).

The phosphorous in lake can be divided into total phosphorous (TP), total reactive phosphorous (TRP), total dissolved phosphorous (TDP), soluble reactive phosphorous (SRP) and particle phosphorous etc. (Carrick et al., 1993). SRP is basically positive phosphate, and it has long been considered that the phosphate is a biological element that can be directly used by biomass. TP includes dissolved and suspended solid phosphorus, and TDP does not include suspended solid (insoluble) phosphorus. The phosphorus in lake sediments is mainly in the form of adsorption, organic-P, Fe-P, Ca-P, and Al-P (Reitzel et al., 2006; Zhang et al., 2012). When phosphorous enter a lake ecosystem variable physical-chemical processes, including release, decomposition or desorption, will happen, and thus accelerate the extent of eutrophication (Reitzel et al., 2006; Wu et al., 2008; Emily et al., 2014). The migration and transformation of phosphorous in sediment-water interface plays an important role in phosphorous endogenous release, such as the phosphorous in the upper $2 \mathrm{~cm}$ sediments in a shallow lake is very easy to diffuse into overlying water through the sediments re-suspension (Xie et al., 2002; Gao et al., 2002; Marcus et al., 2004; Zhang et al., 2013; Testa et al., 2013; Carolina et al., 2012; Wu et al., 2014). The migration and transformation of phosphorus between sediments and overlying water is a dynamic equilibrium process. The release of internal phosphorus in sediments mainly through the following four ways: (1) the release of Fe-P by the change of redox conditions (Reitzel et al., 2006), (2) the release of Fe-P and $\mathrm{Ca}-\mathrm{P}$ by the variable $\mathrm{pH}$ value (Drewry et al., 2009), (3) the degradation of organic matter or mineralization of organic phosphorus (Sun et al., 2007), and (4) the transformation by microbes (Sonderdaard et al., 2003).

In addition, shallow lake is easy to be influenced by hydrodynamic disturbances (Temporetti et al., 2013), which alters the $\mathrm{pH}$, temperature, dissolved oxygen and other environmental factors that can easily influence the processes of phosphorous exchange between lake sediments and overlying water, and therefore, have a significant effect on eutrophication (Xie et al., 2002; Reitzel et al., 2006; Zhang et al., 2013; Tesa et al., 2013). Human activities, especially some water conservancy projects, can critically change the hydrodynamic condition of lakes (Qin et al., 2002). By changing the physical and chemical conditions of sediments and overlying water and even the amount of re-suspended sediments, the sediment transport and release of phosphorus in the sediments are affected, which can aggravate the extent of eutrophication (Qin et al., 2002; Zheng et al., 2004; Temporetti et al., 2013; Li et al., 2013; Huang et al., 2014). Under the strong disturbances, the concentration of SS and TP in the overlying water increased significantly and even several times (Fan et al., 2002; Sun et al., 2007; Pang et al., 2008a; Pang et al., 2008b; Zhang et al., 2008; Jiang et al., 2010). During 
particle re-suspension, the release of internal phosphorus and absorption of phosphorus in overlying water happened simultaneously (Qin et al., 2004; Liang et al., 2013). Nowadays, the studies of the hydrodynamic disturbance on lake sediments are mainly concentrated in wind waves and velocity, but few studies have been conducted on the disturbance caused by water level. Presently, the simulation of phosphorous release from lake sediments is mainly conducted by three methods: the oscillation method, wave flume method, and annular flume method. The oscillation method and wave flume method have a high cost because they require a mass of samples. The annular flume method simulates an infinite lake surface and the flow field is kept uniform.

Many studies have already shown that the construction of the Three Gorges Dam caused the hydrological conditions of Poyang Lake to change obviously as for the variation of the Yangtze River's hydrological conditions (Dai et al., 2015; Du et al., 2014; Tang et al., 2015). So, in this study, in order to analyze the associations between hydrodynamic conditions and the release characteristics of internal phosphorous, a two-way annular flume device was used to investigate the effects of variable water levels and velocities on the phosphorus release from lake sediments. The sediments and water sample were sampled from Poyang Lake outlet region where Poyang Lake enters the Yangtze River. Poyang Lake connects to the Yangtze River at Hukou where the variation of Poyang Lake's hydrological conditions is most apparent. Though the simulation, we want to get helpful data to provide the basic parameters for estimating sediment phosphorus release in a basin scale and afford theoretical basis of eutrophication research and control.

\section{Materials and methods}

\subsection{Study site}

Poyang Lake is the largest freshwater lake in China, and it exchanges water with the Yangtze River in its drainage basin (Cai et al., 2007). Poyang Lake not only regulates the flood state of the Yangtze River, but also affects material and energy exchange of the Yangtze River (Dai et al., 2015). On the other hand, changes in conditions of the Yangtze River also alter available water resources and the aquatic ecosystem in Poyang Lake. After the construction of the Three Gorges Dam, the hydrodynamic conditions of shallow lakes in the middle and lower reaches of the Yangtze River have been changed significantly, so it is valuable and of practical significance to study the release characteristics of phosphorus in Poyang Lake sediments under variable water levels and velocities. Samples of water and surface sediments were collected from the outlet region of Poyang Lake (P) (29 44'31"N, 116 $\left.12^{\prime} 44^{\prime \prime} \mathrm{E}\right)$ (Figure 1).

\subsection{Experimental equipment and principle}

The two-way annular flume device is consisted of three parts: upper plate, lower plate and drive control system (Figure 2). The outside diameter was $120 \mathrm{~cm}$, inside diameter was $80 \mathrm{~cm}$, the width of groove was $20 \mathrm{~cm}$, and the depth of groove was $40 \mathrm{~cm}$. The water groove was made of organic glass. The upper plate was covered by the water surface and the height could be adjusted according to the experiment requirements. In order to explore the effects of water level and velocity, water samples were harvested from several holes at different 


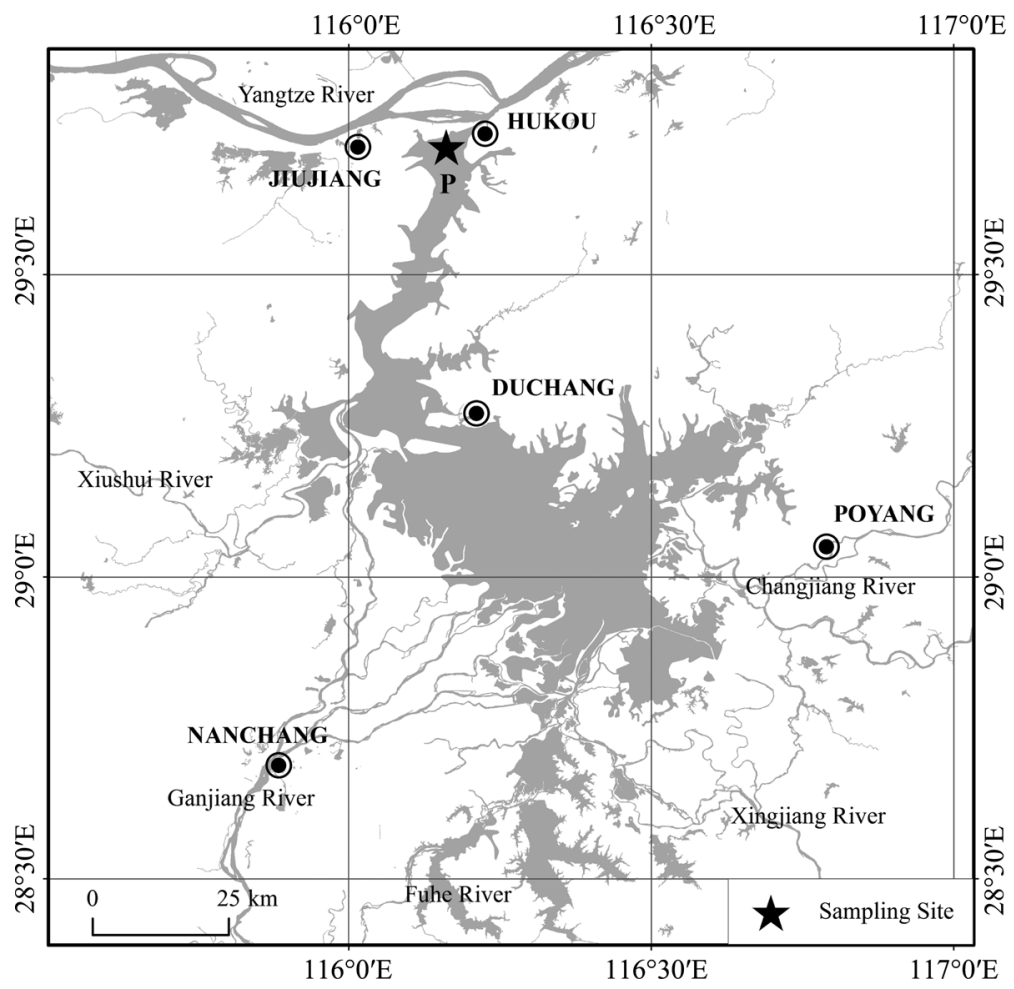

Figure 1 The location and sampling site of Poyang Lake (April 2014)
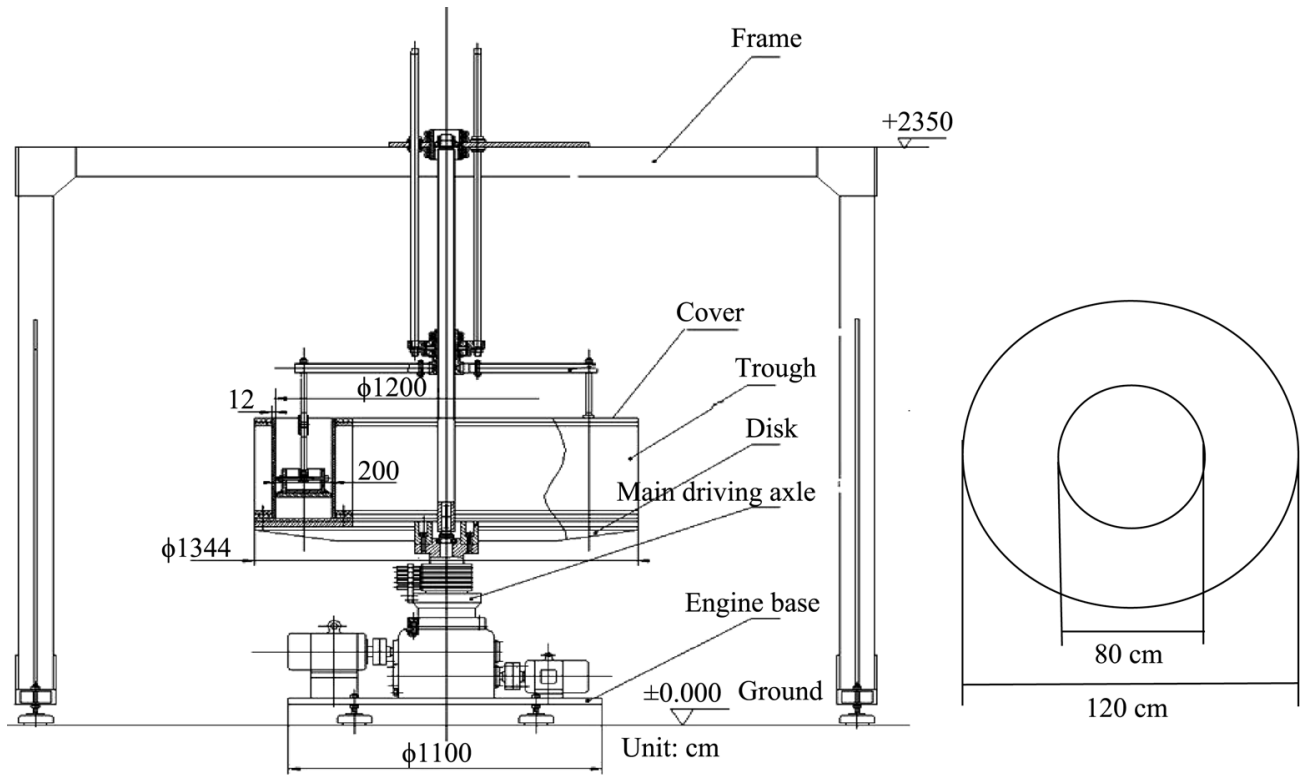

Figure 2 The structure of two-way annular flume device

depths of the water groove. The upper plate and lower plate rotated in opposite directions to produce two centrifugal forces in opposite directions. Additionally, a uniform flow field could be formatted by regulating the relative rotating speed of the upper and lower plates. Consequently, the device could simulate release characteristics of phosphorus in sediments of Poyang Lake under variable water levels and velocities. 


\subsection{Experiment methods}

2.3.1 Sampling and preparation

The experiment was conducted in April 2014 in Nanjing Institute of Geography and Limnology, Chinese Academy of Science. Samples of water (approximately $150 \mathrm{~L}$ ) and surface sediments (about $100 \mathrm{~kg}$ ) were collected from the outlet region of Poyang Lake $\left(29^{\circ} 44^{\prime} 31^{\prime \prime} \mathrm{N}\right.$, $\left.116^{\circ} 12^{\prime} 44^{\prime \prime} \mathrm{E}\right)$. The surface sediments were sampled from the upper $10 \mathrm{~cm}$ sediment by Peterson grab (HAD-XDB0201D). The total $150 \mathrm{~L}$ of water sample were collected from three layers: the water surface, middle of water volume and $0.5 \mathrm{~m}$ above the bottom by Patalas bottle sampler. The average density of sediments was $1.74 \mathrm{~g} / \mathrm{cm}^{3}$, and the average moisture content was $44.68 \%$. Sediments and water sample were respectively stored in polyethylene storage tanks at $2^{\circ} \mathrm{C}$. The sediment samples were mixed and filled to the bottom of the flume of the two-way annular flume device with a thickness of $6 \mathrm{~cm}$, and then, the water samples were added over the sediment using a siphon. The sediment and water within the device were left for two days in order to restore to a sediment-water interface similar to that in the lake.

\subsubsection{Experimental set-up}

(1) Simulation of variable water levels

The velocity of the water flow was set to $0.3 \mathrm{~m} / \mathrm{s}$. Four water levels, $10,15,20$ and $25 \mathrm{~cm}$, were studied in order of low to high water levels. Each treatment was applied for $60 \mathrm{~min}$, after which samples were collected from overlying water, sediment-water interface, and pore water. The experiment was designed with two replicates for each treatment.

(2) Simulation for variable velocities

The level of the overlying water was $15 \mathrm{~cm}$. Nine water flow velocities, $0,0.1,0.15,0.2$, $0.25,0.3,0.35,0.4$ and $0.5 \mathrm{~m} / \mathrm{s}$, were studied in the order of low to high velocities. Each velocity was applied for $60 \mathrm{~min}$, after which samples were collected from overlying water, sediment-water interface, and pore water. Each treatment was studied in duplicate.

The locations of sampling were at depths of $6 \mathrm{~cm}, 17 \mathrm{~cm}$ and $3.5 \mathrm{~cm}$ from the bottom of the sink. The samples of $3.5 \mathrm{~cm}$ were representative of pore water samples, $6 \mathrm{~cm}$ were representative of sediment-water interface water samples, and $17 \mathrm{~cm}$ were representative of overlying water samples. Due to the volume limitation of the experiment device, after each sampling, equal amount of deionized water was slowly added to the sink.

\subsection{Measurements and statistical analysis}

TP and TDP were measured using the molybdenum anti-spectrophotometric method after digestion in alkaline potassium per sulfate. SRP was quantified through spectrophotometry after passing water samples through a GF/C filter. SS were obtained by drying the solid residues collected from the $\mathrm{GF} / \mathrm{C}$ filtration at $105^{\circ} \mathrm{C}$. The $\mathrm{pH}$ was measured using a PB-21 precision pH meter (Szmant, 1996). R studio (Server v 0.98.1091) was used to analyze the data and draw figures.

The sediments release equation (Li et al., 2004) is:

$$
r=\left[V\left(C_{n}-C_{0}\right)+\sum_{j=1}^{n} V_{t}\left(C_{j-1}-C_{a}\right)\right] / A \times t
$$


where $r$ is the release rate $\left(\mathrm{mg} /\left(\mathrm{m}^{2} \mathrm{~d}\right), V\right.$ is the water sample volume in the annular flume (L), $C_{n}$ is the concentration of nutrients in the $n$th water sample $(\mathrm{mg} / \mathrm{L}), C_{0}$ is the initial nutrient concentration $(\mathrm{mg} / \mathrm{L}), V_{t}$ is the volume of water sample $(\mathrm{L}), C_{j-1}$ is the concentration of nutrients in the $(j-1)$ th water sample $(\mathrm{mg} / \mathrm{L}), C_{a}$ is the concentration of nutrients in the original water $(\mathrm{mg} / \mathrm{L}), t$ is the release time $(\mathrm{d})$, and $A$ is the area of the sediment-water interface $\left(\mathrm{m}^{2}\right)$.

\section{Results and discussion}

\subsection{The characteristics of sediments and overlying water}

Table 1 shows the basic characteristics of sediment and overlying water samples two days after analysis of the mixed sediment samples placed on the bottom of the flume of the twoway annular flume. The average density and moisture content of the sediment samples were $1.74 \mathrm{~g} / \mathrm{cm}^{3}$ and $44.68 \%$, respectively. The concentrations of TP in overlying water $(17 \mathrm{~cm})$, sediment-overlying interface $(6 \mathrm{~cm})$ and pore-water $(3.5 \mathrm{~cm})$ were all greater than $0.02 \mathrm{mg} / \mathrm{L}$. These concentrations defined Poyang Lake in a state of eutrophication (Carrick et al., 1993). The concentration of phosphorous in the sediment was much higher than that in overlying water, indicating that the amount of endogenous phosphorous was large and the release of endogenous phosphorous was a potential important source of lake eutrophication.

Table 1 The basic analysis of sediments and overlying water (April 2014)

\begin{tabular}{|c|c|c|c|c|c|}
\hline \multirow{2}{*}{ Sampling site } & \multirow{2}{*}{$\mathrm{pH}$} & SS & $\mathrm{TP}$ & SRP & TDP \\
\hline & & $\mathrm{mg} \mathrm{L}^{-1}$ & $\mathrm{mg} \mathrm{L}^{-1}$ & $\mathrm{mg} \mathrm{L}^{-1}$ & $\mathrm{mg} \mathrm{L}^{-1}$ \\
\hline $17 \mathrm{~cm}$ (Overlying water) & 7.46 & 52.35 & 0.1 & 0.0417 & 0.0611 \\
\hline $6 \mathrm{~cm}$ (Sediment-water interface) & 7.17 & $-*$ & 0.459 & 0.0045 & 0.0252 \\
\hline $3.5 \mathrm{~cm}$ (Pore water) & 6.69 & $-*$ & 0.347 & 0.0419 & $-*$ \\
\hline
\end{tabular}

* represent no measurement.

\subsection{The impact of water level on SS concentration in overlying water}

At low water levels $(10-20 \mathrm{~cm})$, only a small amount of suspended sediments were present, while at high water levels $(20-25 \mathrm{~cm})$, many suspended sediments appeared. Within the experimental range of water level, the SS concentration increased as the water level rose. At the low water level disturbance stage $(10-20 \mathrm{~cm})$, the concentration of SS increased from $2029.65 \mathrm{mg} / \mathrm{L}$ to $2424.15 \mathrm{mg} / \mathrm{L}$, and at the high water level disturbance stage $(20-25 \mathrm{~cm})$, the concentration of SS increased from $2424.15 \mathrm{mg} / \mathrm{L}$ to $4035.85 \mathrm{mg} / \mathrm{L}$, indicating an approximate 1.7-time increase.

When the water level was low, the finer particles were suspended in a very thin layer near the sediment surface. When the water level further increased, some larger particles began rolling along the sediment surface or became suspended in the overlying water. When the water level increased to $25 \mathrm{~cm}$, the smooth surface of the sediments was severely damaged from constant swirling of the silts on the surface, and the overlying water quickly became completely muddy.

\subsection{The impact of water level on TP}

As the water levels rose, the TP concentration in the overlying water also increased (Figure 3). 
The amount of phosphorus released from sediments to the overlying water also slightly increased with the increase of water levels. The lowest TP concentration in the pore water and the highest TP concentration at the sediment-water interface were both found at the water level of $20 \mathrm{~cm}$. Within the experimental range of water level, the TP concentration in the pore water was lower than those in the overlying water and at the sediment-water interface, indicating that the sediment of Poyang Lake was a source of phosphorous, which continuously provided phosphorous.

The variety of TP concentrations represents the comprehensive expression of phosphorous desorption, release, and migration from sediments. At low water levels $(10-20 \mathrm{~cm})$, a small amount of phosphorous in the pore water released into the overlying water through the sediment-water interface, while phosphorus in the particles was desorbed into the pore water. This resulted in an apparent increase in TP concentrations in the overlying water and sediment-water interface. As the water level further increased, the amount of phosphorous released into the overlying water increased proportionally. However, at the highest water level, there was a high SS concentration near the sediments leading to phosphorous adsorption by the particles and a decrease in TP concentration in the sediment-water interface.

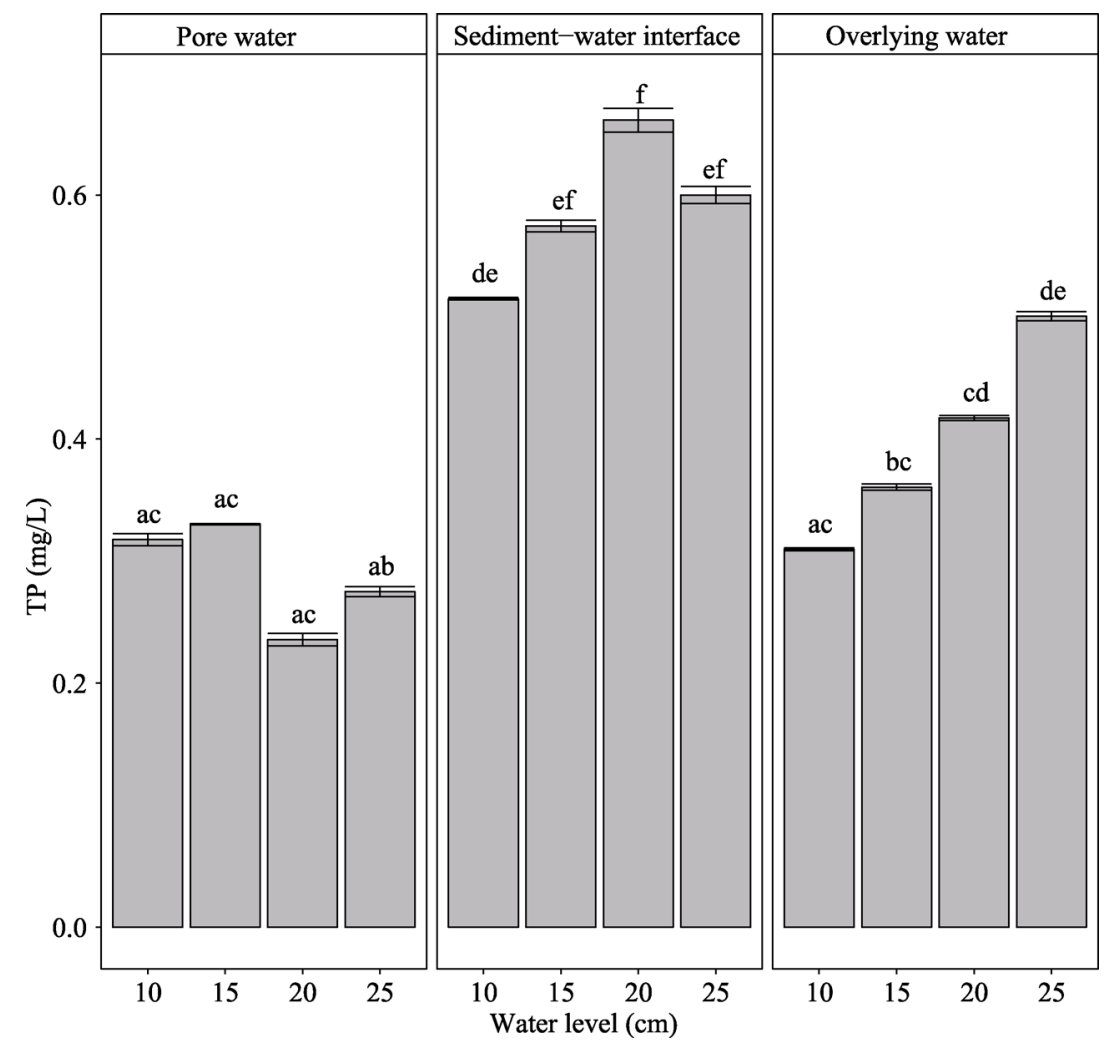

Figure 3 TP concentrations of pore-water, sediment-water interface, and overlying water at each water level (April 2014)

\subsection{The impact of water level on TDP and SRP concentrations}

As the water levels increased, the concentrations of both TDP and SRP in the overlying water and sediment-water interface first decreased from depth of $10 \mathrm{~cm}$ to $15 \mathrm{~cm}$ but then in- 
creased from depth of $15 \mathrm{~cm}$ to $25 \mathrm{~cm}$ (Figure 4). The concentration range of TDP in the overlying water and sediment-water interface was $0.017-0.042 \mathrm{mg} / \mathrm{L}$ and $0.010-0.025 \mathrm{mg} / \mathrm{L}$, respectively. The concentration range of SRP in the overlying water and sediment-water interface was $0.008-0.024 \mathrm{mg} / \mathrm{L}$ and $0.007-0.018 \mathrm{mg} / \mathrm{L}$, respectively.

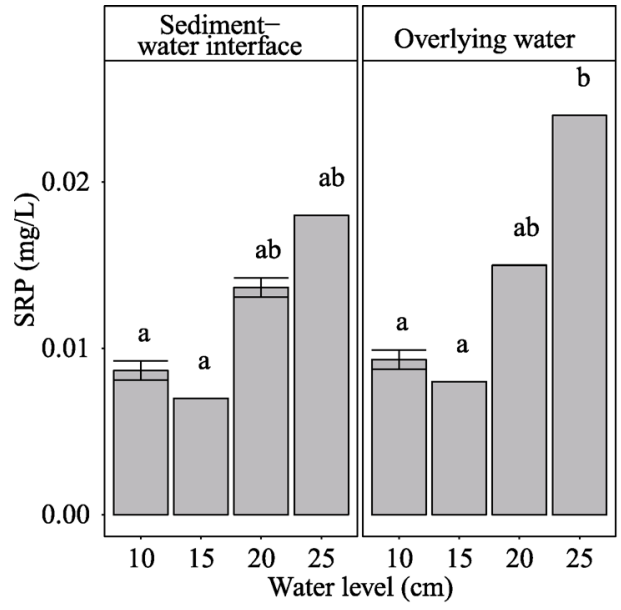

(a) SRP

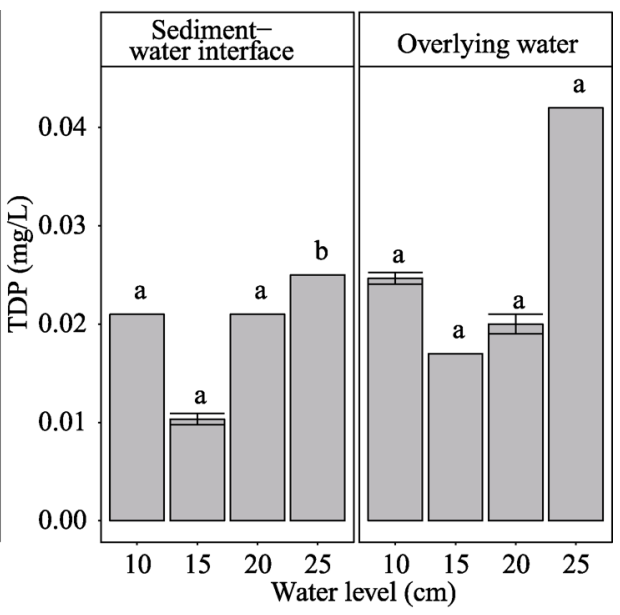

(b) TDP

Figure 4 Concentrations of SRP and TDP in the sediment-water interface and overlying water at the corresponding water levels (April 2014)

Based on the range of TDP and SRP concentrations in overlying water, we determined 15 $\mathrm{cm}$ as the disturbance water level for optimal phosphorus release from sediments since at water levels greater than or less than $15 \mathrm{~cm}$, the concentrations of TDP and SRP varied. Among the different water levels, there were diverse redox environments in sediment-water interface. When the water level was $15 \mathrm{~cm}$, the sediments released the least amount of phosphorous.

The concentrations of TDP and SRP were found to be negatively correlated with $\mathrm{pH}$ (Figure 5), with the highest correlation coefficient of 0.70 between SRP and $\mathrm{pH}$. Phosphorus release from sediments is strongly influenced by $\mathrm{pH}$ through effects on the formation of Fe-P, Al-P, Ca-P and other elements.

\subsection{The impact of velocity on SS concentration in overlying water}

When increasing the water velocity from 0 to $0.5 \mathrm{~m} / \mathrm{s}$, the SS concentration in the overlying water gradually increased. At the low velocity phase $(0-0.2 \mathrm{~m} / \mathrm{s})$, the SS concentration increased from $157.5 \mathrm{mg} / \mathrm{L}$ to $205.85 \mathrm{mg} / \mathrm{L}$ while at the high velocity phase $(0.2-0.5 \mathrm{~m} / \mathrm{s})$, the SS concentration increased from $642.5 \mathrm{mg} / \mathrm{L}$ to $4363.35 \mathrm{mg} / \mathrm{L}$. When velocity increased from zero, the mud in the sediment surface changed from being in a static state to being in a slight suspension, capable of moving into the overlying water. When the velocity was low, a small amount of particles rolled on the sediment surface. Only some of these particles became suspended, causing the water body to become slightly turbid. With the increase in velocity, much more particles moved on the sediment surface and became suspended in the water body, causing much more turbidity. 

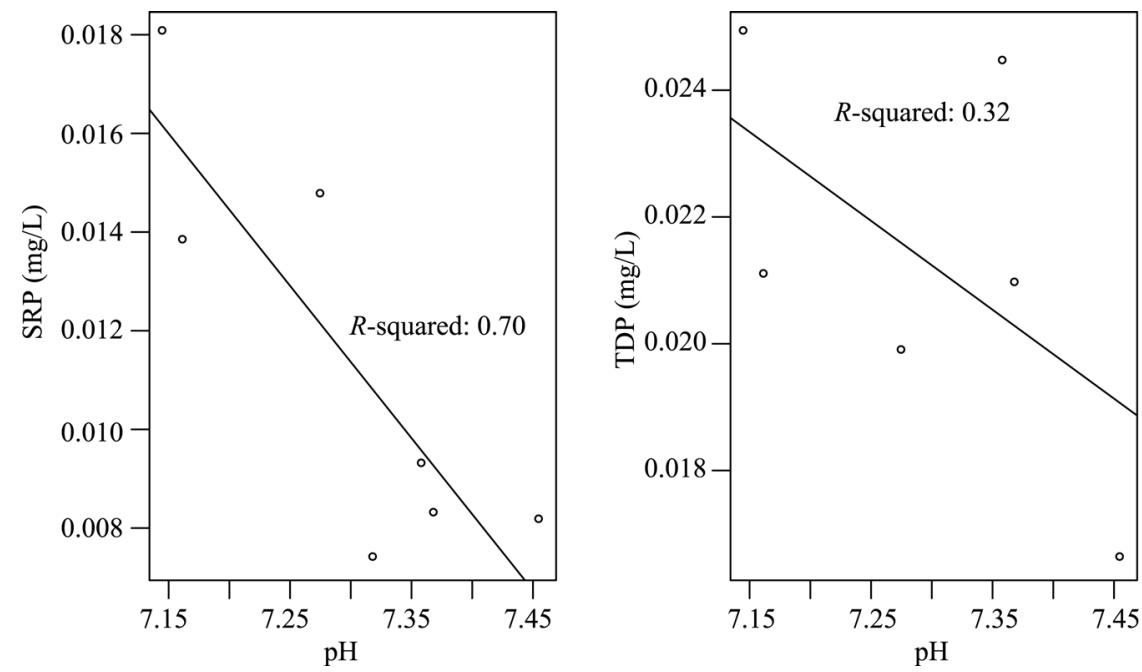

Figure 5 Correlation analysis between concentrations of SRP or TDP and $\mathrm{pH}$

\subsection{The impact of velocity on TP concentrations}

When increasing the velocity from 0 to $0.5 \mathrm{~m} / \mathrm{s}$, the TP concentration in the overlying water increased from $0.11 \mathrm{mg} / \mathrm{L}$ to $0.44 \mathrm{mg} / \mathrm{L}$, about 4 times. The lowest $\mathrm{TP}$ concentration at the sediment-water interface $(0.18 \mathrm{mg} / \mathrm{L})$ occurred at $0.15 \mathrm{~m} / \mathrm{s}$, and the maximum concentration $(0.75 \mathrm{mg} / \mathrm{L})$ appeared at the initial velocity of $0 \mathrm{~m} / \mathrm{s}$. However, the TP concentration in the pore water changed without trend, and collectively, there was little change (Figure 6).

When velocity increased from 0 to $0.1 \mathrm{~m} / \mathrm{s}$, the TP concentrations increased in the pore water, reduced drastically in the sediment-water interface, and rose rapidly in the overlying water. These observations can be explained that phosphorous absorbed by the particles was released into pore water, and phosphorous entered the overlying water through sediment re-suspension at the sediment-water interface. As velocity further increased, phosphorous absorbed by the sediment particles continually released into pore water, and phosphorous from the pore water began moving into overlying water through the sediment-water interface, which was under velocity turbulence. At the velocity of $0.4 \mathrm{~m} / \mathrm{s}$, the TP concentrations in the overlying water, at sediment-water interface, and in pore water all reduced, which indicated that the release of phosphorous from sediments had already reached its maximum value. The high velocity of water body caused a great amount of sediment particles to enter overlying water, and these particles adsorbed dissolved phosphorous, leading to a decrease in the TP concentration at the sediment-water interface and in the overlying water.

\subsection{The impact of velocity on TDP and SRP concentrations}

From the velocities 0 to $0.5 \mathrm{~m} / \mathrm{s}$, the TDP concentrations in the overlying water varied between 0.019 and $0.038 \mathrm{mg} / \mathrm{L}$, with an average value of $0.025 \mathrm{mg} / \mathrm{L}$. The minimum concentration of TDP was $0.019 \mathrm{mg} / \mathrm{L}$, found at $0.4 \mathrm{~m} / \mathrm{s}$. The TDP concentration at the sediment-water interface changed unpredictably with changes in velocity; however, when considering only 0 to $0.5 \mathrm{~m} / \mathrm{s}$, there was an increase (Figure 7).

Similarly to the changes of TDP concentrations, the SRP concentrations in the overlying water varied between 0.015 and $0.036 \mathrm{mg} / \mathrm{L}$ with an average value of $0.024 \mathrm{mg} / \mathrm{L}$ and a 


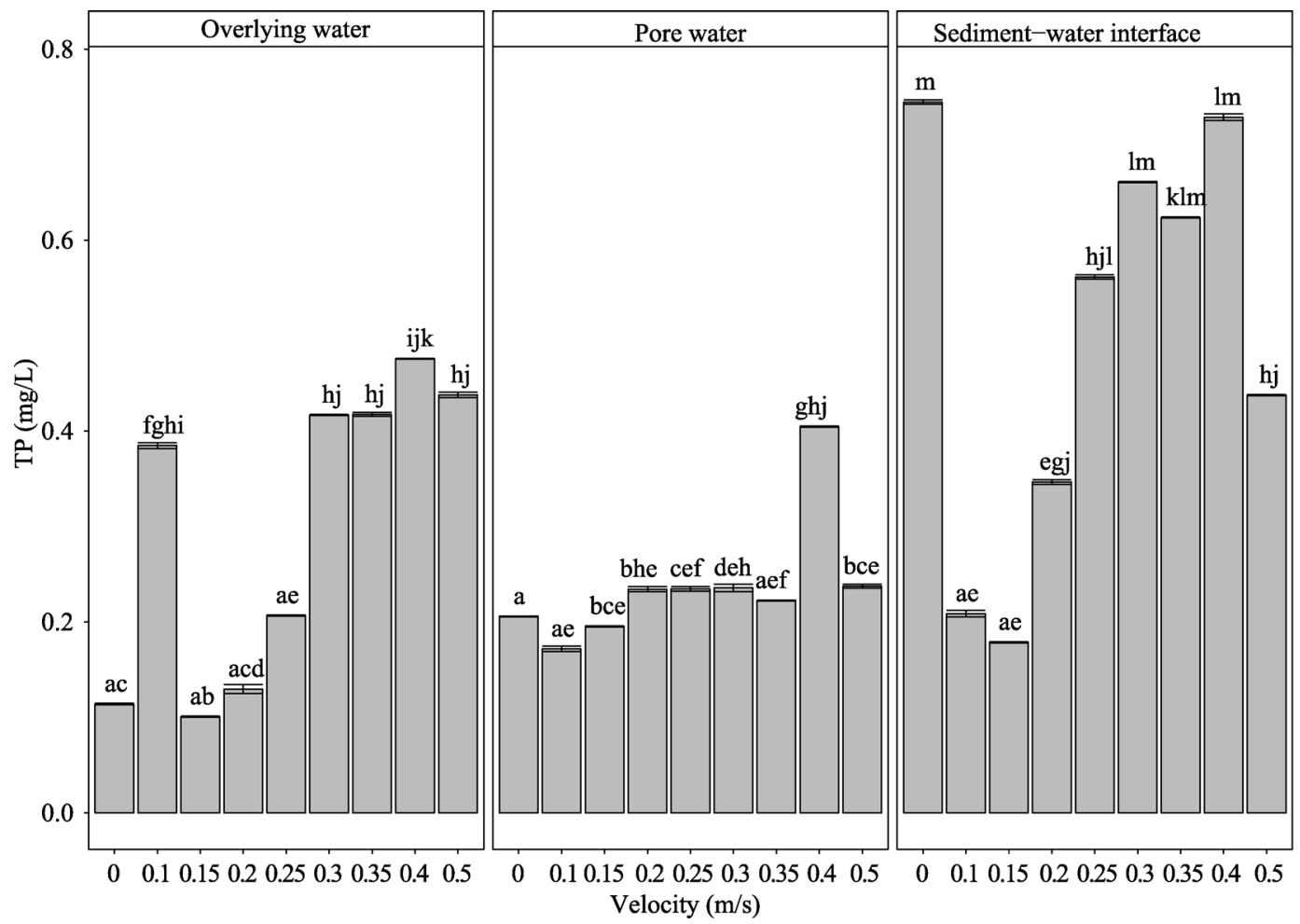

Figure 6 TP concentrations of overlying water, sediment-water interface and overlying water at corresponding velocities (April 2014)
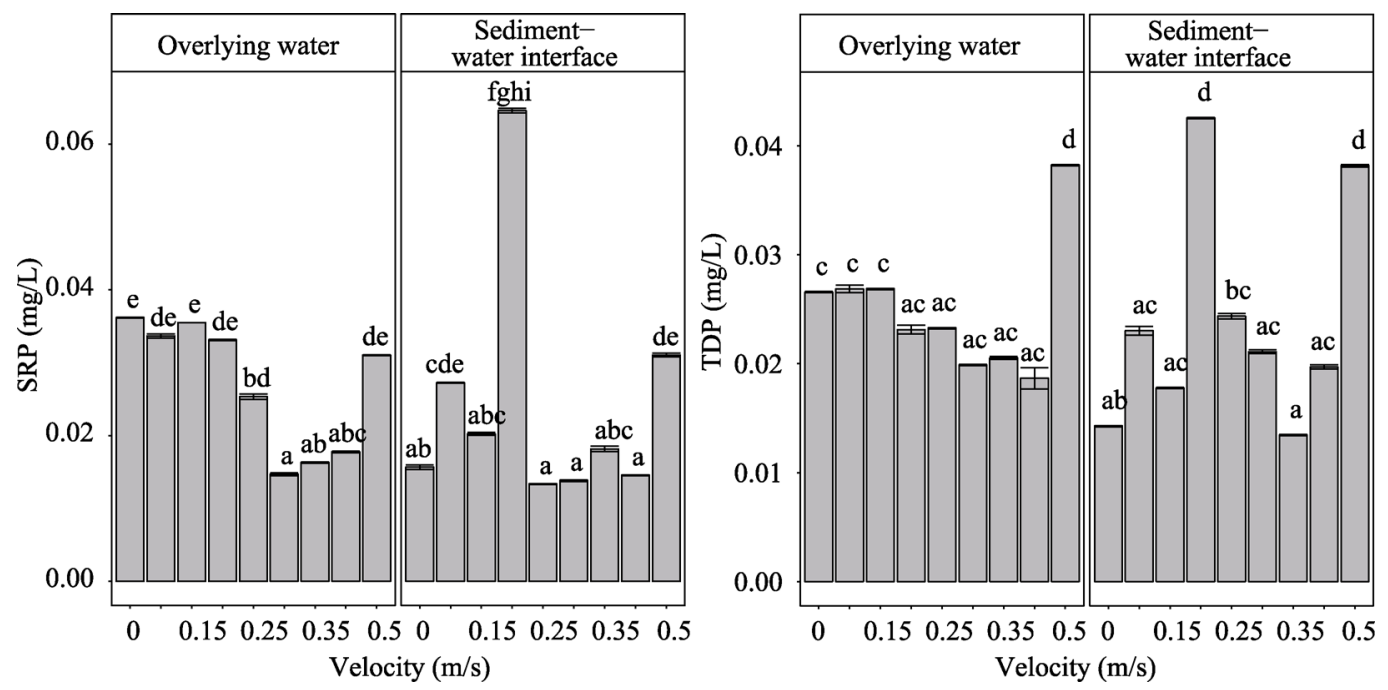

Figure 7 Concentrations SRP and TDP of overlying water and sediment-water interface at the corresponding velocities (April 2014)

minimum concentration of $0.015 \mathrm{mg} / \mathrm{L}$ at $0.3 \mathrm{~m} / \mathrm{s}$. The SRP concentration at the sediment-water interface also varied unpredictably with increases in velocity. The range of SRP concentrations at the sediment-water interface was $0.013-0.065 \mathrm{mg} / \mathrm{L}$ with an average value of $0.024 \mathrm{mg} / \mathrm{L}$. 
The concentrations of both TDP and SRP negatively correlated with $\mathrm{pH}$ value, as well as water level. TDP and SRP concentrations decreased with increases in velocity during which the amount of phosphorous released from sediments was low and showed a decreasing trend.

Shallow lakes can be easily influenced by hydrodynamic conditions, and the release capability increases with the strong disturbance intensity. When the sediments suspend, phosphorous release from sediments and sorption of particles into the overlying water both occur; this is why there is not a sustaining increase or decrease trend of TDP and SRP. When the disturbance intensity was low, the source of phosphorous in the overlying water mainly came from sediments. When the disturbance intensity enhanced, more particles suspended into overlying water and adsorbed dissolved phosphorous, at the same time, oxygen concentration in the overlying water recovered, and then iron, manganese and other metal elements were oxidized to other forms with high phosphorous adsorption capacity. Increases of TDP and SRP were the results of phosphorous release from sediments and the adsorption of particles and metal elements.

\subsection{Effects of water level and velocity on the phosphorous release rate from sediments}

Examination of the relationship between the TP concentration and water level as well as that of the phosphorous release rate and water level (Figures 3 and 8) indicated a few points. Firstly, low water level turbulences $(10-20 \mathrm{~cm})$ caused a low phosphorous release rate from sediments, and the release rate increased with the increase of water level. Secondly, high water level turbulences $(20-25 \mathrm{~cm})$ caused re-suspension of sediments, which in turn released phosphorous into the water body. Finally, high water levels accelerated the release of phosphorous from sediments with the highest release rate of $4.13 \mathrm{mg} /\left(\mathrm{m}^{2} \mathrm{~d}\right)$.

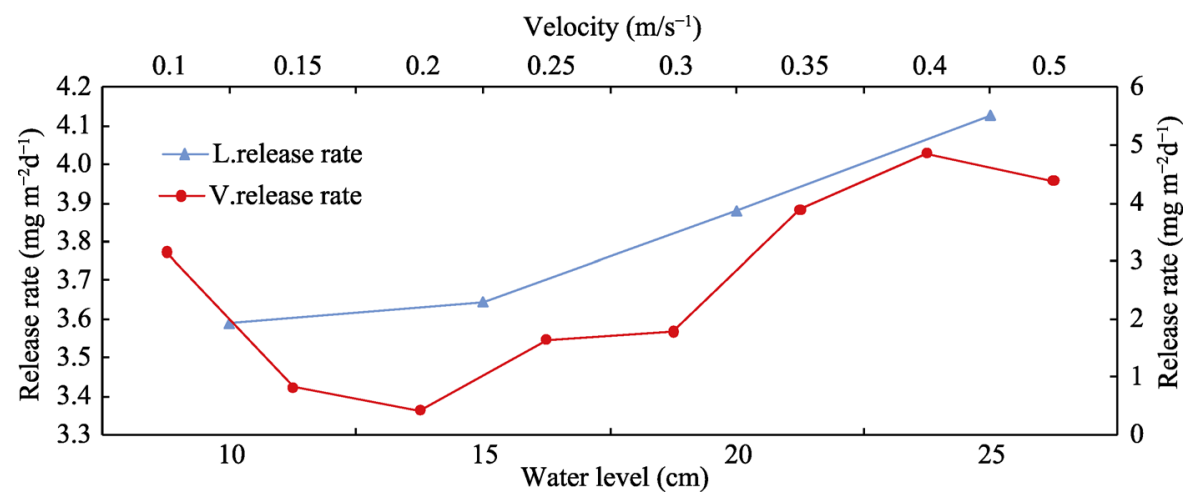

Figure 8 Phosphorous release rate from sediments expressed as a function of water level/velocity

By analyzing the relationship between the TP concentration and velocity as well as that of the phosphorous release rate and velocity (Figures 6 and 8), we found that at low velocity turbulences $(0-0.2 \mathrm{~m} / \mathrm{s})$, sediments barely moved and only a small amount of phosphorous was released into the overlying water. Thus, the release rate was low, and the lowest release rate was $0.43 \mathrm{mg} /\left(\mathrm{m}^{2} \mathrm{~d}\right)$. When the velocity turbulence increased, sediments re-suspended and caused the increase of phosphorous release rate, while at the same time, phosphorous absorbed by sediment particles was also desorbed into pore water. At high velocity turbulences $(0.2-0.5 \mathrm{~m} / \mathrm{s})$, the desorption of sediment particles first reached its maximum value 
before the TP concentration began to decrease in the pore water and overlying water due to the lack of phosphorous source. At the velocity of $0.4 \mathrm{~m} / \mathrm{s}$, the release rate was $4.86 \mathrm{mg} /\left(\mathrm{m}^{2} \mathrm{~d}\right)$ and started to decrease. The highest release rate was about 11 times the lowest release rate, similar to the results reported by Pong et al. (2008) and Reddy et al. (1996).

The relationship between the phosphorous release rate from sediments and water level/velocity was modeled using the curve fitting method and the parameters were consistent with the second and third parabolic equations, respectively (Table 2). The first derivative of these two equations was set to zero, and the optimal water level and velocity were calculated.

Table 2 Simulation of phosphorous release rate under variable water levels and velocities

\begin{tabular}{ccccc}
\hline Parameters & Independent variables & Fitted equations & $\begin{array}{c}\text { Correlation } \\
\text { coefficients }\left(R^{2}\right)\end{array}$ & Minimum $(\mathrm{cm}$ or m/s) \\
\hline \multirow{2}{*}{ Release rate } & Water level $(\mathrm{cm})$ & $y=0.0479 \mathrm{x}^{2}-0.0547 x+3.5876$ & 0.99 & 0.57 \\
& Velocity $\left(\mathrm{m} \mathrm{s}^{-1}\right)$ & $y=-0.0914 x^{3}+1.4025 x^{2}-5.7575 x+7.5701$ & 0.96 & 0.20 \\
\hline
\end{tabular}

\section{Conclusions}

As the water level and velocity varied, the physicochemical characteristics of the overlying water and sediment-water interface changed. The increase in water level and velocity caused an increase in the SS concentration as well as the $\mathrm{pH}$ value in the overlying water while the changes of the sediment-water interface and pore water varied. As well, the TP concentration in the overlying water and phosphorous release rate from sediments both increased with the increase in water level. During the increase in velocity, the phosphorous release rate reached the maximum value at $0.4 \mathrm{~m} / \mathrm{s}$. The simulation experiment indicated that the concentrations of both TDP and SRP were negatively correlated with $\mathrm{pH}$ value, and the amount of phosphorous release showed a decreasing trend.

The phosphorous release rate with either the water level or velocity was fitted with a best curve fitting method, and water level and velocity were found to be consistent with the second and third parabolic equations, respectively. The optimum water level at the velocity of $0.3 \mathrm{~m} / \mathrm{s}$ was calculated to be $0.57 \mathrm{~cm}$, and the optimum velocity at the water level of $15 \mathrm{~cm}$ was $0.2 \mathrm{~m} / \mathrm{s}$.

\section{Acknowledgments}

We would like to thank the Nanjing Institute of Geography and Limnology, Chinese Academy of Sciences for providing the experimental conditions to us. We also appreciate the guidance from LI Wei and DING Shiming within the whole experiment process.

\section{References}

Cai H, Zhu D, Zhang X et al., 2007. Dynamics analysis of the ecological capacity in Po-yang Lake Nature Reserve based on RS and GIS. Acta Ecologica Sinica, 27(11): 4751-4757. (in Chinese)

Carolina M M, Martinez G, 2012. Organic carbon, phosphorus and nitrogen in surface sediments of the marine-coastal region north and south of the Paria Peninsula, Venezuela. Environmental Earth Sciences, 65(2): 429-439.

Chen Y, Tang L, 2005. Study prospect on removing and transforming characteristics of nitrogen and phosphorous 
in sediment-water interface. Journal of Yunnan Agricultural University, 20(4): 527-533. (in Chinese)

Dai X, Wan R, Yang G, 2015. Non-stationary water-level fluctuation in China's Poyang Lake and its interactions with Yangtze River. Journal of Geographical Sciences, 25(3): 274-288.

Du Y L, Zhou H D, Peng W Q et al., 2015. Modeling the impacts of the change of river-lake relationship on the hydrodynamic and water quality revolution in Poyang Lake. Acta Scientiae Circumstantiae, 35(5): 1274-1284. (in Chinese)

Drewry J J, Newham L T H, Croke B F W, 2009. Suspended sediment, nitrogen and phosphorus concentrations and exports during storm-events to the Tuross estuary, Australia. Journal of Environmental Management, 90(2): 879-887.

Emily K R, Monika I, Paul H et al., 2014. Phosphorus speciation in a eutrophic lake by ${ }^{31} \mathrm{P}$ NMR spectroscopy. Water Research, 62: 229-240.

Fan C, Zhang L, Yang L et al., 2002. Simulation of internal loadings of nitrogen and phosphorus in a lake. Oceanolgia et Limnologia Sinica, 33(4): 370-378. (in Chinese)

Gao X, Chen Z, Zhang N et al., 2002. Heavy metals and phosphorus in tidal flat sediments of the Yangtze estuary. Journal of Geographical Sciences, 12(4): 472-478.

Huang J, Xu Q, Xi B et al., 2014. Effects of lake-basin morphological and hydrological characteristics on the eutrophication of shallow lakes in eastern China. Journal of Great Lakes Research, 40(3): 666-674.

Jiang Y, Li X, Xing Y et al., 2010. Impacts of disturbance on release of total nitrogen and total phosphorus from surficial sediments of Dongping Lake. Environmental Science and Technology, 33(8): 41-44.

Kim S H, Hwang S J, Shin J K et al., 2007. Effects of limiting nutrients and N:P ratios on the phytoplankton growth in a shallow hypertrophic reservoir. Hydrobiologia, 581: 255-267.

Li D, Huang Y, 2013. Phosphorus uptake by suspended sediments from a heavy eutrophic and standing water system in Suzhou, China. Ecological Engineering, 60: 29-36.

Li Y, Pang Y, Lu J et al., 2004. On the relation between the release rate of TN, TP from sediment and water velocity. Scientia Limnologica Sinica, 16(4): 318-324. (in Chinese)

Liang W, Wang Z, Jiao Z et al., 2013. Adsorption of phosphorus in sediment re-suspension under sudden expansion flow conditions. Journal of Hydrodynamics, 25(1): 112-117.

Marcus S, Christiane H, 2004. The influence of sorption processes on the phosphorus mass balance in a eutrophic German lowland river. Water, Air, and Soil Pollution, 155: 291-301.

Pang Y, Yan R, Yu Z et al., 2008a. Suspension-sedimentation of sediment and release amount of internal load in lake Taihu affected by wind. Chinese Journal of Environmental Science, 29(9): 2456-2464.

Pang Y, Zhuang W, Han T et al., 2008b. Experiment and model simulation of suspended solids in Taihu Lake under wind-wave disturbance. Chinese Journal of Environmental Science, 29(10): 2743-2748.

Qin B, Hu W, Gao G et al., 2004. Dynamics of the sediment resuspension and the conceptual schema of nutrient release in the large shallow lake Taihu, China. Chinese Science Bulletin, 49(1): 54-64.

Reddy K R, Fisher M M, Ivanoff D, 1996. Resuspension and diffusive flux of nitrogen and phosphorus in a hypereutrophic lake. Journal of Environmental Quality, 25: 363-371.

Reitzel K, Ahlgren J, Gogoll A et al., 2006. Effects of aluminum treatment on phosphorus, carbon, and nitrogen distribution in lake sediment: A P-31 NMR study. Water Research, 40(4): 647-654.

Sonderdaard M, Jensen J P, Jeppesen E, 2003. Role of sediment and internal loading of phosphorus in shallow lakes. Hydrobiologia, 506(1): 135-145.

Sundby B, Gobeil C, 1992. The phosphorus cycle in coastal marine sediments. Limnology and Oceanography, 37(6): 1129-1145.

Sun X, Qin B, Zhu G et al., 2007. Effect of wind-induced wave on concentration of colloidal nutrient and phytoplankton in Lake Taihu. Chinese Journal of Environmental Science, 28(3): 506-511.

Szmant A M, Forrester A, 1996. Water column and sediment nitrogen and phosphorus distribution patterns in the Florida Keys, USA. Coral Reefs, 15(1): 21-41.

Tang C X, Xiong X, Wu N H et al., 2015. Simulation of the impact of the reverse flow from Yangtze River on the 
hydrodynamic process of Lake Poyang. Journal of Lake Sciences, 27(4): 700-710. (in Chinese)

Temporetti P, Snodgrass K, Pedrozo F, 2013. Dynamics of phosphorus in sediments of a naturally acidic lake. International Journal of Sediment Research, 28(1): 90-102.

Testa J M, Brady D C, Di T D M et al., 2013. Sediment flux modeling: Simulating nitrogen, phosphorus, and silica cycles. Estuarine Coastal and Shelf Science, 131: 245-263.

Wetzel R G, 2001. Limnology: Lake and River Ecosystems. 3rd ed. San Diego: Academic Press, USA.

Wu C, Wang Y, Han J et al., 2008. Preliminary study on nitrogen and phosphorus release characteristics from sediment in Beigu wetland. Environmental Science and Technology, 31(4): 10-12.

$\mathrm{Wu}$ D, Hua Z, 2014. The effect of vegetation on sediment resuspension and phosphorus release under hydrodynamic disturbance in shallow lakes. Ecological Engineering, 69: 55-62.

Xie L, Xie P, 2002. Long-term (1956-1999) dynamics of phosphorus in shallow, subtropical Chinese lake with the possible effects of cyanobacteria blooms. Water Research, 36: 343-349.

Xing K, Guo H, Sun Y et al., 2005. Assessment of the spatial-temporal eutrophic character in the Lake Dianchi. Journal of Geographical Sciences, 15(1): 37-43.

Zhang K, Cheng P, Zhong B et al., 2012. Total phosphorus release from bottom sediments in flowing water. Journal of Hydrodynamics, 24(4): 589-594.

Zhang L, Fan C, Wang J et al., 2008. Nitrogen and phosphorus forms and release risks of lake sediments from the middle and lower reaches of the Yangtze River. Scientia Limnologica Sinica, 20(3): 263-270. (in Chinese)

Zhang Y, Yang L, Lei K et al., 2013. Exchange and deposition fluxes of nitrogen and phosphorus across sediment-water interface in lower Yellow River. Journal of Sediment Research, 6: 66-74.

Zheng L, Ye Y, Zhou H, 2004. Phosphorus forms in sediments of the East China Sea and its environmental significance. Journal of Geographical Sciences, 14(1): 113-120. 